\title{
The application of Han Dynasty cultural elements to modern product design
}

\author{
Liling Chen ${ }^{1,2}$, Jinsheng Kang ${ }^{2}$, Leilei Zhang ${ }^{1}$, Mengcheng Wang ${ }^{1}$ Ding Wang $^{2}$ \\ ${ }^{1}$ School of Mechanical Engineering, Northwestern Polytechnical University, China, 710072 \\ ${ }^{2}$ School of Engineering and Design, Brunel University, Uxbridge ,UB8 \\ chenliling@nwpu.edu.cn \\ ${ }^{2}$ Jinsheng.Kang@brunel.ac.uk
}

\begin{abstract}
Chinese Han Culture, as Chinese nation's "core culture", is the cultural symbol of Chinese nation, and played an important role in the history of Chinese cultural development, even in the history of world cultural development. Designing in the Han Dynasty, while inheriting Chinese traditional culture, but also having its unique style, are appreciated and respected by the people nowadays. In a modern society where the design is becoming more diversified, the innovative design based on traditional culture and art has its unique charm and vitality. This paper presented our recent research on the application of Han Dynasty cultural elements to modern product design, reflected the local design connotation of Han Dynasty cultural elements.
\end{abstract}

Keywords- Chinese Han Culture, Product Design, Traditional Cultural Heritage

\section{INTRODUCTION}

The blending of traditional culture and modern product design is a new trend in product design industry today, more and more modern consumer products reflected the integration of design talent and cultural connotation [1]. Modern product design has extended from commodity society to traditional cultural background, it has absorbed the quintessence from Chinese traditional culture to form the creative elements for the design, and injected the positive cultural connotation into design [2]. Han culture, as the Chinese nation's "core culture" is a symbol of Chinese nation, as well as the inheritance and development of ancient Chinese traditional culture [3]. Chinese Han culture is a blend of different cultures from many ethnic groups, and it demonstrated great breadth and applicability. It has both a basic commonality of Chinese national culture and its own unique cultural characteristic and distinctiveness, and it is a brilliant model which makes people unify, makes nation unify, makes diversification unify, its cultural achievements has the largest and deepest impact that any other cultures can't be compared.

A limited number of research on cultural elements and their application on new product design has been carried out. For example, Yair [4] found that crafting knowledge can be explored to stimulate innovative product design. Leong [5] identified three stages in his exploration of traditional Chinese culture as premise for contemporary design. Lee [6] extracted the images of cultural landscape in Taiwan and applied them to consumer product. Hsu [7] proposed a framework for the development of cultural product. Lin [8] studied the transformation of Taiwan aboriginal culture features into modern product design.

The designing in Han Dynasty has a special position in the history of ancient Chinese art and design. It is not only famous for its beautiful styling and superior function, but also for its rich cultural connotations. It is admired by people because it shaped the cultural character of ancient Chinese art design. From both historic culture and historic art point of view, the research on Han Dynasty art design under cultural background has important theoretical value. Unlike the conventional shape, decorative pattern and color studies, this research is a comprehensive exploration of the various categories of art and design under the historical background in Han Dynasty. The research is not only about the lines of Han Dynasty art design, but also the wide range of social backgrounds and cultural implication behind them. These cultural elements and their connotations then were embedded into modern consumer product design, to demonstrate the harmony and unification of the people, society and enviroment, which is the core of Han Dynasty culture. This is the uniqueness of our study.

\section{METHODS}

\section{A. Color analysis of Chinese Han cultural elements}

The most commonly used colors in Han Dynasty were red and black, and this is obvious either from the tomb murals, silk painting, portrait stone painting, or pottery painting. The reasons are as follows:

- The inherent color pigments resources are mainly extracted from hematite, which can be extracted conveniently, because of the widely spread rich resources.

- The concept of Yin and Yang was popular in the Han Dynasty. The theory of Yin, Yang and Five Elements is a simple materialism from the early Qin Dynasty philosophy, it is a theory which explains the origin and change of the universe.

- The theory of Life and Death was also popular in Han Dynasty. The day presents the red color of 
the sun, and the night shows the black color of the dark. The symbolic concept of red and black and the theory of life and death together evolved the people's life and art in Han Dynasty.

From the perspective of human sociology, the red and black are pure color categories. Since the ancient Zhou Dynasty, ritual system by class level prevailed, red and black colors are more in line with the wishes of the ruling class and social etiquette system.
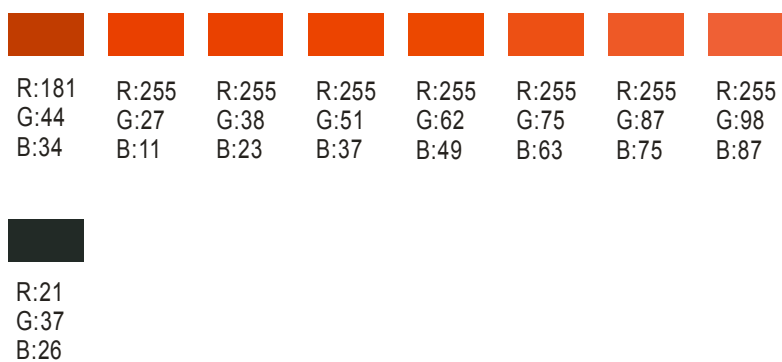

Figure 1 Color of Han Dynasty

Color in Han Dynasty based on red and black (Figure 1) had its objective reasons and subjective reasons, and it showed that people in Han Dynasty dealt with symbolism color and inherent color from the view of traditional concept about color, and in an art manner.

\section{B. Extraction of Chinese Han culture design gene}

- Clouds pattern (Figure 2): the creation of the Han clouds pattern is from the advocating and worship of the gods and nature, the form changed from the "point-like" cloud thunder pattern to the "linear" clouds pattern, and it can be considered that the Han Dynasty is a poetic romantic period in Chinese cloud pattern history.

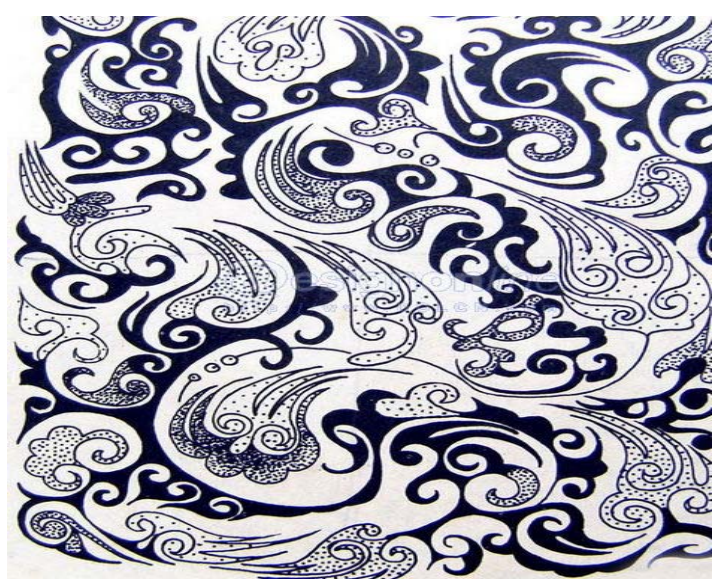

Figure 2 Clouds pattern

- Moire (Figure 3): Moire is an important traditional Chinese pattern. The moire shapes changed from early Qin Dynasty to Han Dynasty, because they were closely related to the social background factors and the level of ideology and crafting at these two dynasties.

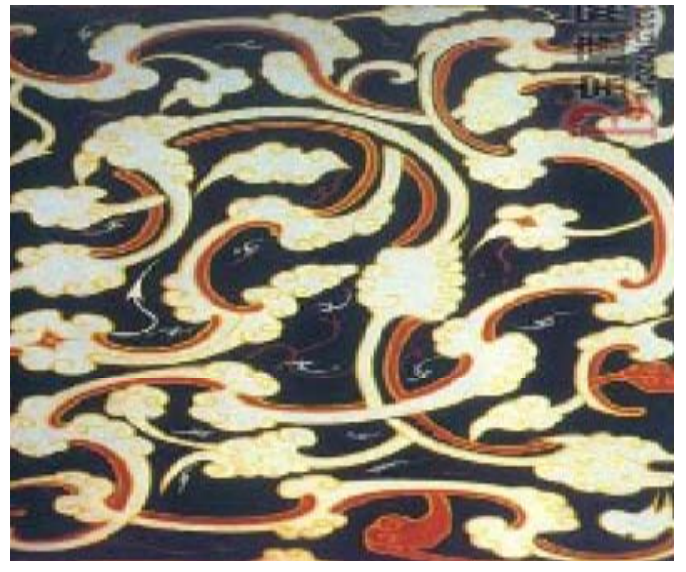

Figure 3 Moire

- Tile-end 4 Mythical Creatures (Figure 4): the Han Dynasty tile-end raised Chinese ancient art to a peak by its quantity, fine quality, distinctive characteristics at the time and the rich cultural connotation. In ancient China, the most exorcizing four creatures were Black Dragon, White Tiger, Rosefinch and Xuanwu [9] .

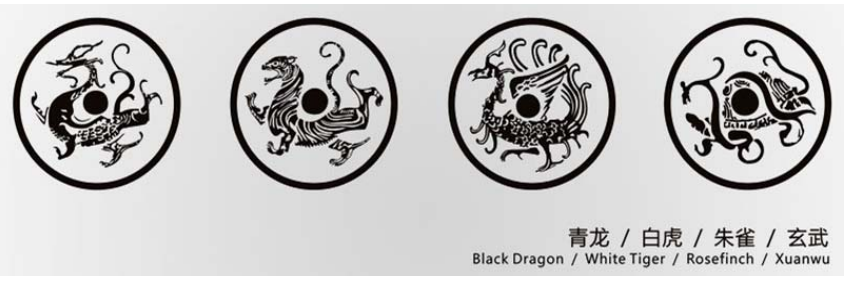

Figure 4 Tile-end 4 Mythical Creatures

Black Dragon was the ancient god of the Orient. The dragon is the totem of the Chinese nation, and it is a symbol of the Chinese nation and the whole China, starting from the Han Dynasty. The dragon was also identified as the symbol and representative of the emperor.

White Tiger, the ancient god of the West. Its body is like a tiger, and in white, as a noble symbol.

Rosefinch, the ancient god of the south, Its body is like the phoenix, it is the spirital animal.

Xuanwu, the ancient god of the north, it is the Taoist god.

- Bronze censer (Figure 5): It is used for incense and heating in Han Dynasty, mostly owned by palace or rich people. Boshan censer appeared in the mid-Western Han Dynasty, and appeared in large numbers in the tombs of the Han Dynasty. It was prevailing under the incense cultural 
background which developed continuously since the Spring and Autumn Period.

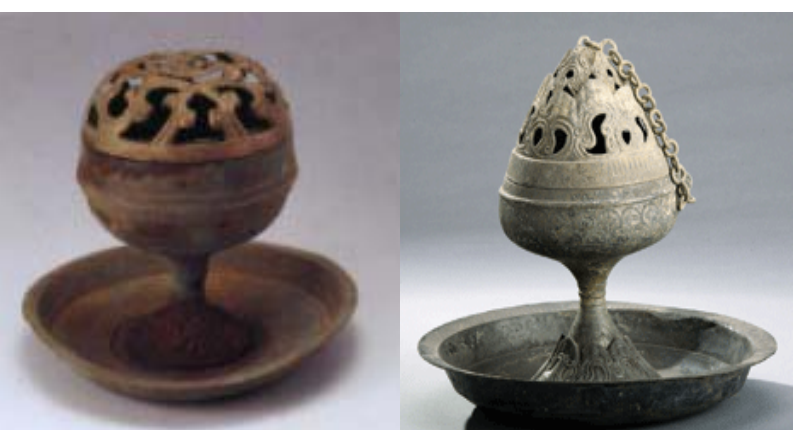

Figure 5 Han Dynasty bronze censer, Boshan censer

\section{PRODUCT DESIGN CASES BASED ON THE LOCALIZATION OF CHINESE HAN CULTURE}

\section{A. Cloud pattern lighting design}

The product is based on modern design theory of minimal cylindrical and square shapes, and the Han Dynasty cloud pattern has been cut out from the lampshad. The light leaks out from the hollow places (cut out), makes clouds pattern shape prominent. The round lamps are made of black metal, with a red metallic shade (Figure 6). The square lamps are made of mahogany material (Figure 7) which showed the traditional Chinese furnishing characteristics, and the material is hard, and of high strength and durability. Among the two, each type of lamps has three different sizes, they are suitable for different environments such as living room, bedroom, and study. The matching with seats and with human body measurements were fully considered in the design of these floor lamps. The matching of colors has a heavy feeling, a sense of security. Considerations were also given in designing these lamps about the usability, portability and convenience to match with to a variety of furniture

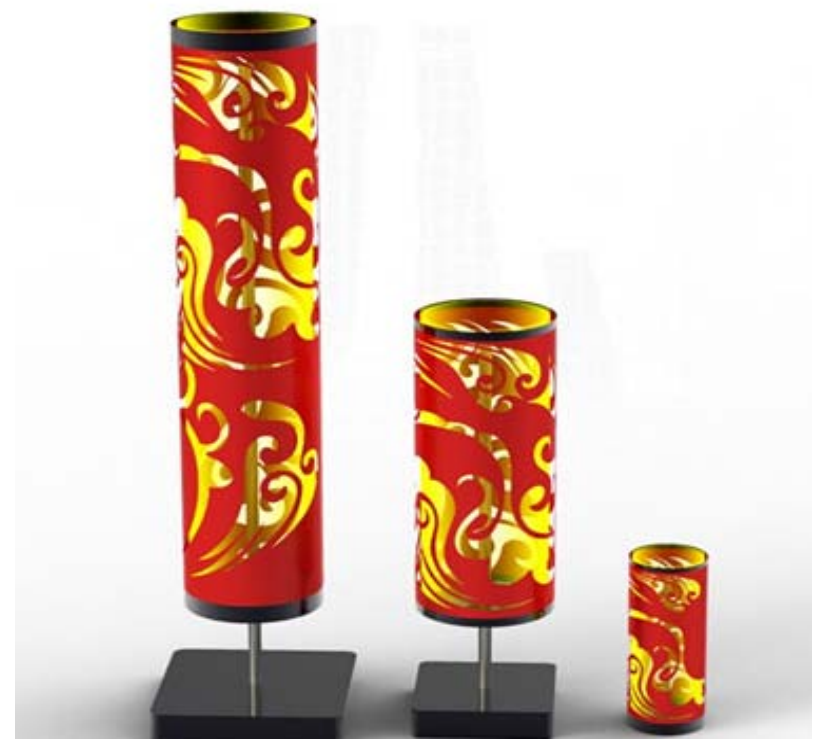

Figure 6 Cloud pattern lighting design one

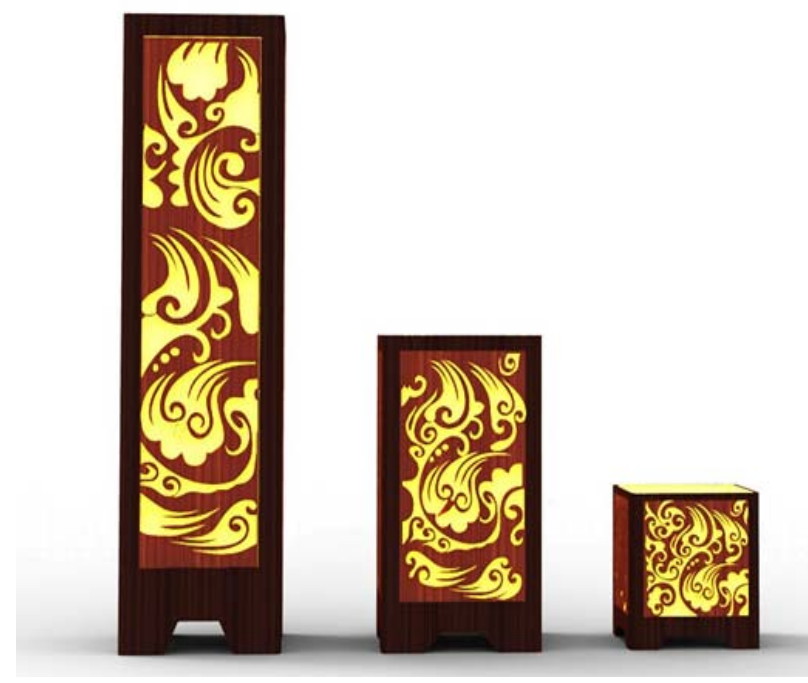

Figure7 Clouds pattern lighting design two

\section{B. Portable tableware design}

Portable tableware, makes dining out more confident about health and hygiene in China. Figure 8 is a portable tableware design. Each chopstick is made of two portions, with a chopstick holder and a removable chopstick tip. The oval chopstick box, chopsticks and spoon are embedded with matching cloud pattern from Han Dynasty culture. The shape and size of chopstick box makes it easy to carry. The chopstick is designed with round stick tip and square head. While the square head is convenient to hold by hand, the four small grooves on the round stick are designed for picking up food conveniently. This tableware is decorated with Han Dynasty cloud patterns with colors mostly red, black and yellow. Made of medical stainless steel with anti-acid property, and with its compact structure, this tableware makes eating out hygiene and enjoyable.

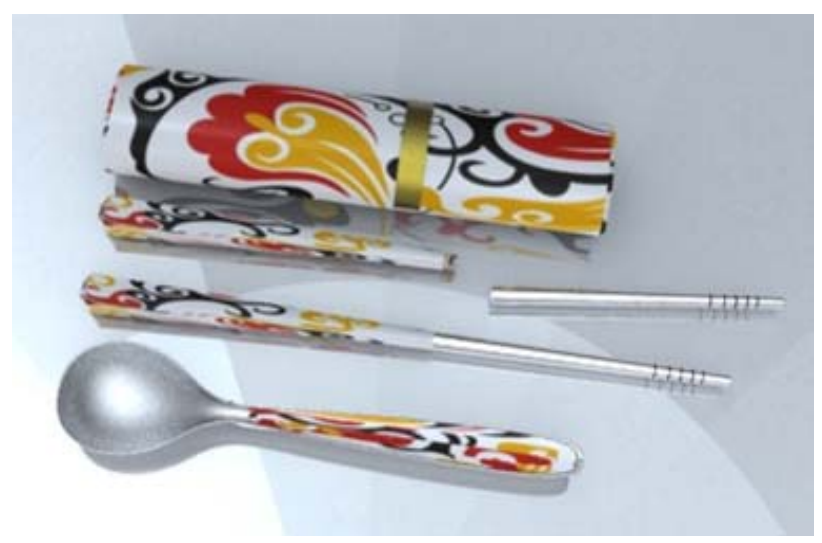

Figure 8 Portable tableware design

\section{Smoked salt crystal lamp design}

Smoked salt crystal lamps are small table lamps, and people put them on a desk or nightstand (Figure 9). It absorbed the beauty of the Han Dynasty styling censers, used modern crystal salt landscaping materials which can 
clean air, beautify the environment, it makes the Han culture perfectly integrated with modern materials.

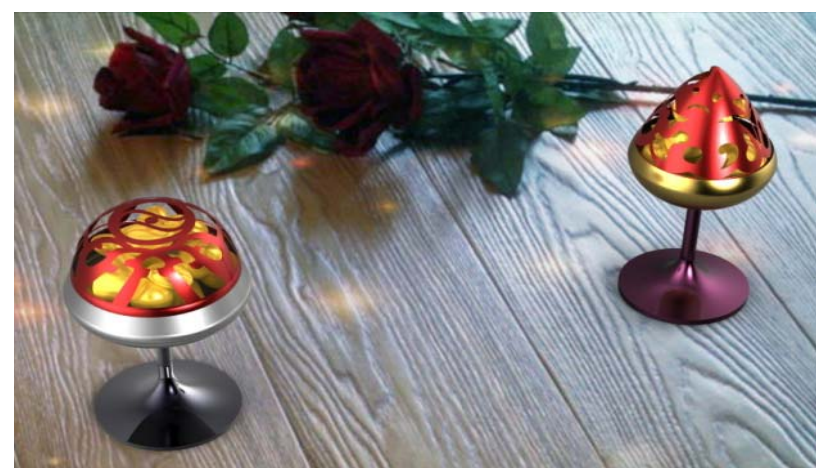

Figure 9 Smoked salt crystal lamp design

The overall color tone is red and black, and it represents the simplicity, noble and warm, which was the main color style in the Han Dynasty design. The lighting effect is yellow, the light color is strong. The shade material is durable and reflectance, with a stable support base. This lamp has a small size, it is easy to move and suitable for different situations. The crystal salt material not only can clean air and beauty the environment as a decoration in the shade, but also act as a natural propagating source of negative ions. These negative ions can improve the indoor air quality, and the electromagnetic waves and light waves of crystal salt lamps can adjust human body and mind, and this fits the green design concept.

\section{Mug design}

Figure 10 shows an S-shaped mug designed ergonomically, it is an appealing design which is easy to grip. The material is mainly stainless steel, it is corrosionresistant, and it meets cool aesthetic appreciation of the metal era. The left mug is special because the lid can be used as a cup, there is a red button in the cup mouth with heat dissipation function. Carving the Han Dynasty moire patterns on the cup body makes the cup beautiful. The right mug is designed for people who love tea, it has a small separate net pot to hold the tea-leaves on the rim of the cup, and it is easy to assemble. Carved with Dragon, White Tiger, Rosefinch, Xuanwu patterns, it used black metallic as main paint color, with red buttons and silver bottom.

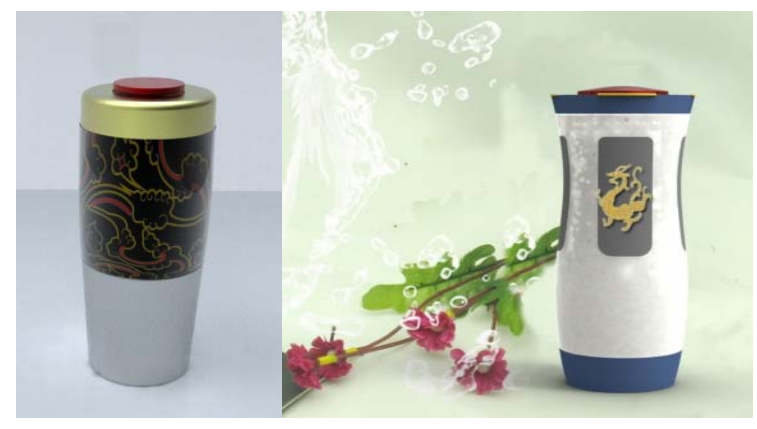

Figure 10 Mug design

\section{DISCUSSION AND CONCLUSION}

The traditional Chinese art system is deep, broad and profound. Chinese culture and art elements will play an important part in modern design in the spirit of traditional design. The historic Han culture is a fusion of the essence of various types of "universal" culture, showing the universal extensity and applicability. Chinese Han Culture, as the Chinese nation's "core culture", embodies the nation's spirit of making progress and selfimprovement. Chinese Han Culture is important to the history of Chinese cultural development, even to the history of world cultural development. It has generated and will continue to generate extensive and far-reaching impact to both China and the world.

Designing with regional local culture becomes more important than ever when product design facing an era of globalization, in order to make product distinctive with characteristics. The designing concept of Chinese elements theory has more localized features. The Han Dynasty elements replete with Chinese cultural spirit will bring the Chinese design brand to the world, integrate it into the world, and influence the world. The research reported here is just a beginning towards this direction.

\section{REFERENCES}

[1] Haojie Tan, Ying Cheng, Introduction to modern design methods, Beijing Institute of Technology Press, 2007.

[2] Jun Zheng, Decorative Art History of the Han Dynasty, Shandong Fine Arts Publishing, 2006.

[3] Jingping Wang, Hong Li, The Han Style. Shaanxi People's Publishing, 2004.

[4] Karen Yair Mike Press, Anne Tomes .Crafting competitive advantage:Crafts knowledge as a strategic resource. Design Studies Volume 22, Issue 4, July 2001, Pages 377-394.

[5] Benny Ding Leong , Hazel Clark. Culture-Based Knowledge Towards New Design Thinking and Practice-A Dialogue .Design Issues Summer 2003, Vol. 19, No. 3: 48-58.

[6] Ying-Jye Lee. Exploration of local culture elements and design of cultural creativity products.Journal of Statistics and Management Systems.Volume 13, Issue 4, 2010.

[7] Chi-Hsien Hsu, Chih-Long Lin, Rungtai Lin .A Study of Framework and Process Development for Cultural Product Design. Internationalization, Design and Globa Development Lecture Notes in Computer Science.Volume 6775, 2011, pp 55-64.

[8] Rung-Tai Lin, Transforming Taiwan Aboriginal Cultural Features into Modern Product Design: A Case Study of a Cross-cultural Product Design Model. International Journal of Design Vol. 1(2) August 2007.

[9] Yufeng Liu, Artistic qualities and cultural function research of ceramic pattern of Qin and Han dynasties., Chinese ceramic industry, 2008(1) 